\title{
The Relationship between the Chemical Structures of Dihydropyrazine Derivatives and DNA Strand-Breakage Activity
}

\author{
Tadatoshi Yamaguchi, ${ }^{*, a}$ Shigeru Ito, ${ }^{b}$ Nobuhiro Kashige, ${ }^{c}$ Kazuhide Nakahara, ${ }^{d}$ and \\ Kazunobu HARANO ${ }^{a}$
}

${ }^{a}$ Faculty of Pharmaceutical Sciences, Sojo University; Kumamoto 860-0082, Japan: ${ }^{b}$ Institute of Biomaterials and Bioengineering, Tokyo Medical and Dental University; Tokyo 101-0062, Japan: ${ }^{c}$ Faculty of Pharmaceutical Sciences, Fukuoka University; Fukuoka 814-0180, Japan: and ${ }^{d}$ Faculty of Pharmaceutical Sciences, Kumamoto University; Kumamoto 862-0973, Japan.

Received September 23, 2006; accepted December 27, 2006; published online January 10, 2007

Dihydropyrazine, a compound derived from sugars, possesses DNA strand-breakage activity. The relationship between the activity as assayed using pBR 322 ccc-DNA and the chemical structures of derivatives of dihydropyrazine (DHPs) has been investigated. The addition of $\mathrm{Cu}^{2+}$ enhanced the activity remarkably. The introduction of a methyl or phenyl group onto the DHP ring or a cyclohexyl group fused onto the DHP ring also increased the activity. These properties indicated that the activity was due to the facility of electron release from the DHP ring, followed by radical generation. The determination of ionization potential and electrostatic potential values, and bond dissociation energy via semi-empirical MO calculations suggested strongly that the activity is induced by a DHP ring structure that contains a configuration suitable for hyperconjugation.

Key words dihydropyrazine; DNA strand-breakage; ionization potential; bond dissociation energy; semi-empirical calculation method

We have previously described the DNA strand-breaking activity $^{1,2)}$ and other characteristics (e.g., generation of radical species $^{3,4)}$ and high chemical reactivity ${ }^{5-7)}$ ) of dihydropyrazines (DHPs) in vitro. More recently, we have examined the biological effects of DHPs, such as induction of apoptosis ${ }^{8)}$ and mutagenesis, ${ }^{9}$ in vivo. The various phenomena caused by DHPs cannot be explained on the basis of one particular reaction mechanism. In this paper, we attempt to illustrate the relationship of the chemical structure of DHPs on DNA strand scission.

\section{Experimental}

Synthesis of Dihydropyrazine Derivatives The dihydropyrazine derivatives (Fig. 1) employed were synthesized by the condensation of diketones and diamines. 2,3-Dihydro-5,6-dimethylpyrazine (1), 2,3-dihydro-2,5,6- trimethylpyrazine (2), 2,3-dihydro-2,2,5,6-tetramethylpyrazine (3), cis-2,3dimethyl-5,6,7,8,9,10-hexahydroquinoxaline (4-cis) and trans-2,3-dimethyl5,6,7,8,9,10-hexahydroquinoxaline (4-trans) were synthesized by the method of Yamaguchi et al. ${ }^{1)}$ Their derivatives $\left(\mathbf{3 a},{ }^{7)} \mathbf{2 a},{ }^{7)} \mathbf{1} \mathbf{c}^{7{ }^{7}} \mathbf{1 b}^{5)}\right.$ ) and dihydrofructosazine ${ }^{10)}$ were synthesized according to literature procedures, and 1a was synthesized from aminoacetone hydrochloride ${ }^{11)}$ by dehydrochlorination. ${ }^{10)}$ Similar methods were also used to replace the methyl group of 1 and 4-trans by a phenyl group to generate 2,3-dihydro-5-methyl-6phenylpyrazine $(\mathbf{5})^{12)}$ and trans-2-methyl-3-phenyl-5, 6,7,8,9,10-hexahydroquinoxaline $(\mathbf{6}),{ }^{12}$ respectively (Table 1), and the mixture $(7)^{13)}$ of 2,3,5,6,7,8- and 1,2,3,5,6,7-hexahydroquinooxalines (Chart 3).

Assay of DNA Strand-Breaking Activity The method to assess the DNA strand-breakage activity of DHPs, using a covalently closed circular duplex DNA (ccc-DNA) of plasmid pBR322 was described previously. ${ }^{1)}$

Semi-empirical MO Calculations The ionization potential (IP) based on Koopman's theorem, electrostatic potential (ESP), heat of formation $\left(\Delta H_{\mathrm{f}}\right)$ and bond dissociation energy (BDE) values based on AM1, PM3 and<smiles>CC1=NC2CCCCC2N=C1C</smiles>

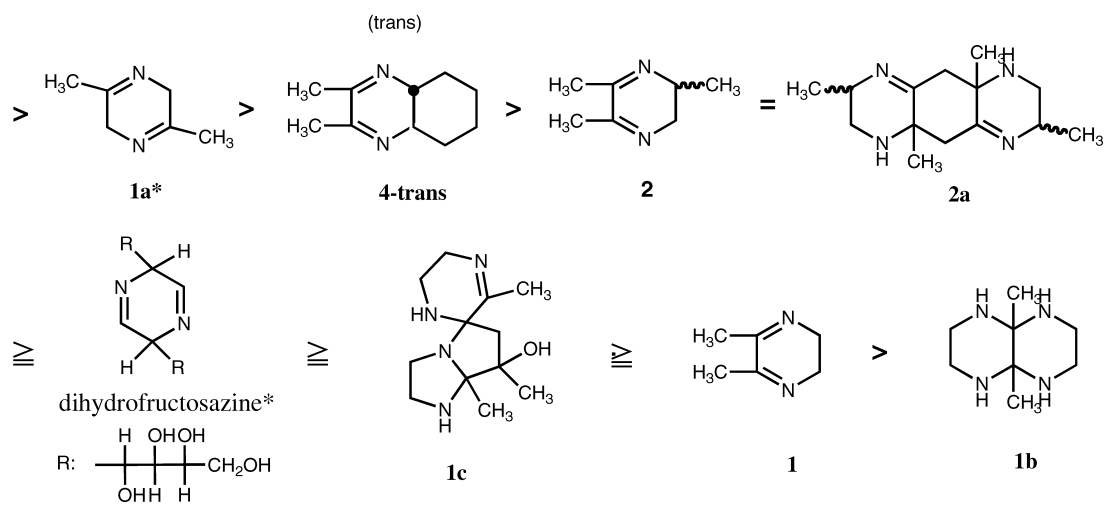

Fig. 1. The Order of DNA Strand-Breakage Activity

* Existence as a single material was not possible to due to air oxidation to the aromatic compound, as observed in the UV spectrum. 


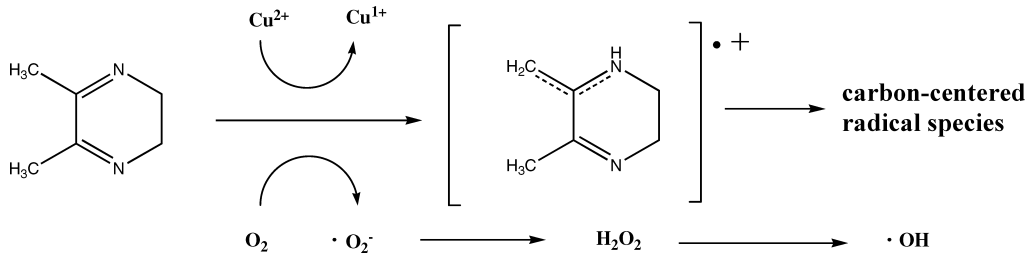

Chart 1. The Process of Radical Generation from Dihydropyrazine Having Mutual Interaction with $\mathrm{Cu}^{2+}$

PM5 calculations were discussed as a measure of the DNA strand-breakage activity. The calculations were performed using MacSpartan Pro and WinMOPAC 3.5.

\section{Results and Discussion}

DNA strand-breakage activity was assayed using pBR322 ccc-DNA. The addition of $\mathrm{Cu}^{2+}$ enhanced the activity remarkably. The presence of various inhibitors ${ }^{1)}$ suggested that the reactive intermediate might be a radical species, and indeed, oxygen radicals and carbon-centered radicals were detected in the ESR spectrum ${ }^{3)}$ as shown in Chart 1. From this it can be deduced that the DNA strand-breaking reaction occurs via the attack of a radical species ${ }^{4)}$ generated from the interaction of DHPs with $\mathrm{Cu}^{2+}$ and dissolved oxygen in the reaction system.

Figure 1 shows the order of DNA strand-breakage activity $^{1)}$ of DHPs under millimolar concentrations in the presence of $\mathrm{Cu}^{2+}(1 \mathrm{~mm})$. As shown in the order $(\mathbf{3}>\mathbf{2}>\mathbf{1})$ of compounds, the increase in activity is due to the introduction of electron-donating methyl groups on the DHP ring. Accordingly, $\mathrm{Cu}^{2+}$ was reduced to $\mathrm{Cu}^{1+}$ by electron transfer from the DHPs. ${ }^{1}$ The electron density (ED) in the DHP ring can be estimated by the ED of the nitrogen atom on which the electron is localized. Therefore, the ED and electrostatic potential (ESP) of two nitrogen atoms were calculated by AM1 as follows: (compound: ED/ESP) 1: $-0.15 /-0.52$ and $-0.15 /-0.52 ; 2$ : $-0.15 /-0.55$ and $-0.15 /-0.59 ; 3:-0.15 /$ -0.62 and $-0.15 /-0.56$. Although the ED values were similar, the order of total ESP values was $\mathbf{3}(0.62+0.56)>\mathbf{2}$ $(0.55+0.59)>1(0.52+0.52)$, which is in agreement with their DNA strand-breakage activity. The order of 4 -cis $>$ the mixture of 4-cis and-trans $>\mathbf{4}$-trans, and $\mathbf{1} \mathbf{a}>\mathbf{1}$ implies that the activity was also affected by steric factors. The order shown in Fig. 1 suggests that there are three factors relating to the activity: electron density in the DHP ring, sterics, and mutual interaction with $\mathrm{Cu}^{2+}$.

The introduction of a phenyl group, which is not an electron-donor, into the dihydropyrazine skeleton increased the activity also, as shown in Table 1 . The order of the breakage activity is $\mathbf{5}>\mathbf{1}$ and $\mathbf{6}>\mathbf{4}$-trans. Because compound $\mathbf{5}$ has the weakest reducing ability ${ }^{4)}$ among DHPs 1, 2, 3 and 5, its activity is attributed to the facility of radical generation and the subsequent release of an electron from the dihydropyrazine ring and not the electron density of the dihydropyrazine ring. This will be discussed later.

Ionization potential was used as another measure of the relative activity for DNA scission. The ionization potential (IP) values on the basis of the AM1, PM3 or PM5 calculations are summarized in Table 2. The order $(\mathbf{3}>\mathbf{2}>\mathbf{1}, \mathbf{4}-$ cis $>$ 4-trans, 3a $>\mathbf{2 a}$ ) for the breakage activity shown in Fig. 1 is entirely opposite to the order $(\mathbf{3}<\mathbf{2}<\mathbf{1}, \mathbf{4}$-cis $<\mathbf{4}$-trans, $\mathbf{3} \mathbf{a}<\mathbf{2 a})$ of the IP values shown in Table 2 . These data indi-
Table 1. Effect on the Cleaving Activity of an Additional Methyl Group and Replacement of a Methyl Group with a Phenyl Group

\begin{tabular}{|c|c|c|c|}
\hline \multirow{2}{*}{ Test compound } & \multirow{2}{*}{ Conc. (mм) } & \multicolumn{2}{|c|}{ Remained ccc-DNA (\%) } \\
\hline & & $3 \mathrm{~h}$ & $+\mathrm{Cu}^{2+} 1 \mathrm{~h}$ \\
\hline & 0.1 & 100 & 95 \\
\hline & 1.0 & 94 & 47 \\
\hline & 10.0 & 84 & 21 \\
\hline & 0.1 & 100 & 92 \\
\hline & 1.0 & 91 & 44 \\
\hline & 10.0 & 63 & 0 \\
\hline & 0.1 & 97 & 64 \\
\hline & 1.0 & 91 & 0 \\
\hline & 10.0 & 71 & 0 \\
\hline & 0.1 & 99 & 93 \\
\hline & 1.0 & 96 & 71 \\
\hline & 10.0 & 86 & 0 \\
\hline & 0.1 & 99 & 45 \\
\hline & 1.0 & 69 & 0 \\
\hline & 10.0 & 24 & 0 \\
\hline & 0.1 & 100 & 84 \\
\hline & 1.0 & 100 & 60 \\
\hline & 10.0 & 96 & 5 \\
\hline & 0.1 & 100 & 84 \\
\hline & 1.0 & 93 & 23 \\
\hline & 10.0 & 65 & 0 \\
\hline
\end{tabular}

Plasmid pBR322 ccc-DNA was incubated with various concentrations of DHP in $50 \mathrm{~mm}$ Tris- $\mathrm{HCl}$ buffer ( $\mathrm{pH} 7.2$ ) at $37^{\circ} \mathrm{C}$ for $1 \mathrm{~h}$ with $1 \mathrm{~mm} \mathrm{CuCl}_{2}$ or $3 \mathrm{~h}$ without $\mathrm{CuCl}_{2}$. It is indicated that the breakage activity is as strong as the amount of remaining cccDNA is small.

Table 2. The Ionization Potential Values Calculated by AM1, PM3 and PM5 Methods, and DNA Breakage Acyivity

\begin{tabular}{lcccc}
\hline \hline \multirow{2}{*}{ Compound } & \multicolumn{3}{c}{ Calc. method } & ccc-DNA \\
\cline { 2 - 4 } & PM3 & AM1 & PM5 & remaining (\%) $)^{a)}$ \\
\cline { 2 - 5 } $\mathbf{1}$ & 9.798 & 9.714 & 9.341 & 95 \\
$\mathbf{1 a}$ & 9.756 & 9.640 & 9.328 & - \\
$\mathbf{1 b}$ & 9.268 & 9.111 & - & - \\
$\mathbf{1 c}$ & 9.023 & 8.728 & - & - \\
$\mathbf{2}$ & 9.776 & 9.630 & 9.298 & 92 \\
$\mathbf{2 a}$ & $9.457-9.517$ & $9.589-9.617$ & - & - \\
$\mathbf{3}$ & 9.721 & 9.565 & 9.229 & 64 \\
$\mathbf{3 a}$ & 9.363 & 9.561 & - & - \\
$\mathbf{4 - c i s}$ & 9.701 & 9.530 & 9.192 & 45 \\
$\mathbf{4 - t r a n s}$ & 9.770 & 9.549 & 9.227 & 84 \\
\hline
\end{tabular}

a) This data was cited from our privious papaer. ${ }^{1)}$ It indicated that the breakage activity is as strong as the amount of remaining ccc-DNA is small. 


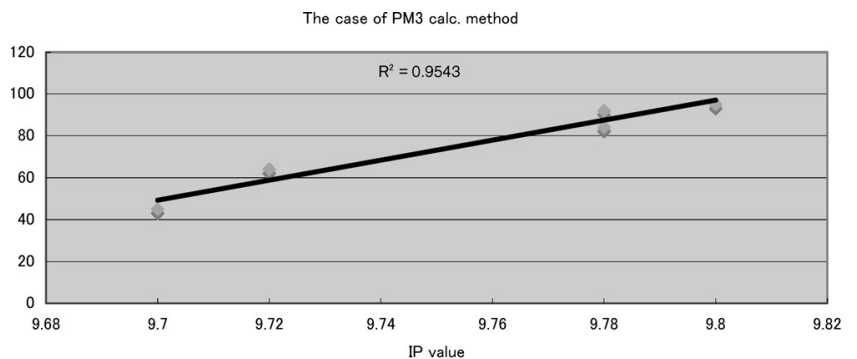

The case of AM1 calc.method

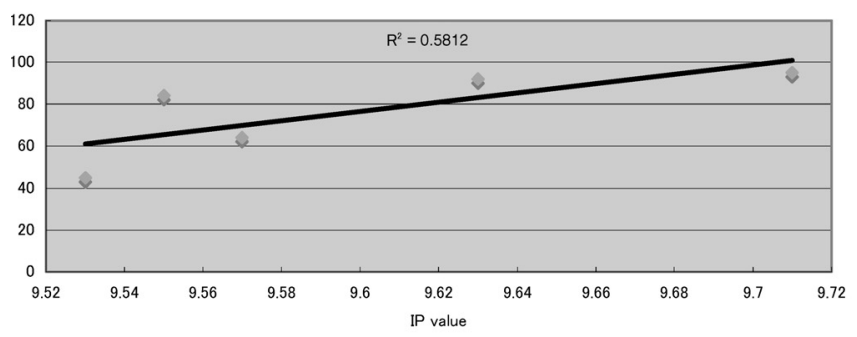

The case of PM5 calc. method

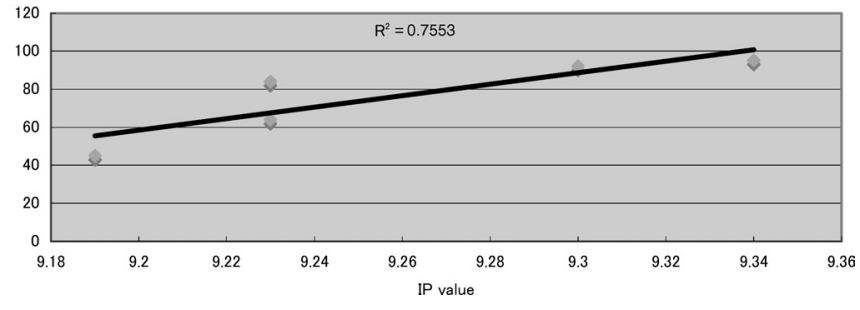

Fig. 2. The Relationship between IP Values and DNA Breakage Activity

cate that the breakage activity increases as the IP value gets smaller, at least in structurally similar compounds. Unfortunately, this idea cannot be applied uniformly to all compounds listed in Fig. 1, because several (1b, 1c, 2a, 3a) are significantly different in their structures from 1 . The relationship between the IP values calculated by PM3, AM1 or PM5 and DNA breakage activity ${ }^{1)}$ were illustrated graphically in Fig. 2, which depicted only five compounds $(\mathbf{1}, \mathbf{2}, \mathbf{3}, \mathbf{4}-\mathrm{cis}, \mathbf{4}-$ trans $)$. The correlation coefficient value $\left(R^{2}=0.9543\right)$ on the case of PM3 calculated IP value is to be preferred over the case of AM1/PM5 calculated one $\left(R^{2}=0.581 / 0.7553\right)$. This suggests that the PM3 method is the most suitable for IP value estimation.

The transformation of the highly reactive DHPs is illustrated in Chart 2. A key intermediate (Int. 1) can be converted into some products such as $\mathbf{1 b}, \mathbf{1 c}, \mathbf{2} \mathbf{a}$ and $\mathbf{3 a}$ upon nucleophilic attack or ene reaction. ${ }^{5-7)}$ The preferential reactivity of DHPs may be enhanced by the formation of an enamine moiety and the breakage activity also might require this isomerization. To test this hypothesis we attempted to synthesize a hexahydroquinoxaline compound, where the exo-type isomer predominates ${ }^{14)}$ due to steric factors in the fused ring (Chart 3).

An oily product (compound 7) showed a mixture of endoand exo-type isomers (as shown in the bottom entry of Table 3 ) in the NMR spectrum. The ratio of endo-7 and exo-7 was $1: 5$ in $\mathrm{CDCl}_{3}$ at room temperature, and varied depending on solvent and temperature. ${ }^{13)}$ The ratio of endo-7 and exo-7 was $1: 1.1$ in an equilibrium solution (in $\mathrm{CDCl}_{3}$ at $50^{\circ} \mathrm{C}$ ). Inspection of the RHF/6-31G* heat of formation $\left(\Delta H_{\mathrm{f}}\right)$ in the gas phase indicated that endo-7 was more stable than exo-7 with a difference of $\Delta H_{\mathrm{f}}=3.74 \mathrm{kcal} / \mathrm{mol}$, although the $\Delta H_{\mathrm{f}}$ of 7 based on PM3 and AM1 indicated the superiority of endotype as shown in Table 3.

Compounds $\mathbf{1}$ and $\mathbf{5}$ actually showed the presence of only the endo-type isomer in the NMR spectra, however 7 showed signals for both the endo- and exo-type structures. Thus, it is clear that the breakage activity of 7 was the strongest among the three DHPs $(\mathbf{1}, \mathbf{5}, \mathbf{7})$. Some derivatives of $\mathbf{7}$ also have been assayed for comparison with derivatives of $\mathbf{1}$ and $\mathbf{5}$ (data not shown). The order of the breakage activity was 7 $>5>1$ (unpublished results). This result indicates that the breakage activity was due to the presence of Int. 1 (exo-type<smiles>O=C1CCCCC1=O</smiles><smiles>NCCN</smiles><smiles>C1=C2NCCN=C2CCC1</smiles><smiles>C1CCC2=NCCN=C2C1</smiles>

exo-7

Chart 3. The Synthesis of Dihydropyrazine Derivatives Which Should be Predictable to Reveal DNA Strand-Breakage Activity

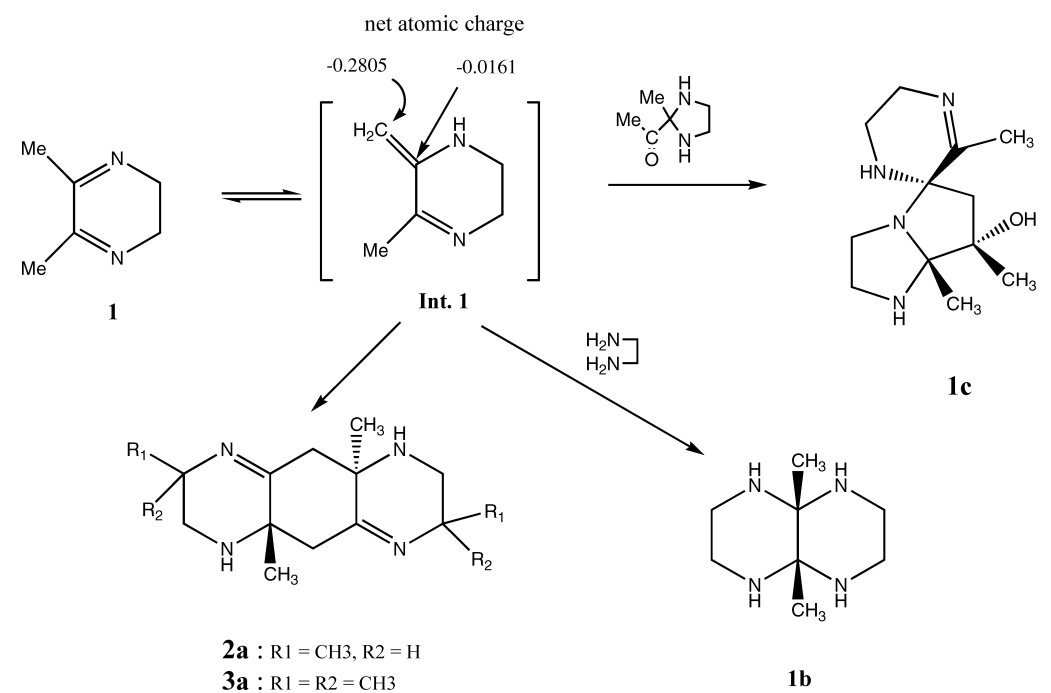

Chart 2. Chemical Reactions via an Intermediate from Dihydropyrazine 
Table 3. Comparison of the Data Calculated by AM1 and PM3 for the endo- and exo-Type DHPs and Pyrazine

\begin{tabular}{|c|c|c|c|c|c|}
\hline \multicolumn{2}{|c|}{ Calculation } & \multirow{2}{*}{ endo-Type } & \multirow{2}{*}{ exo-Туре } & \multicolumn{2}{|c|}{ Calculation } \\
\hline AM1 & PM3 & & & AM1 & PM3 \\
\hline $\begin{array}{c}33.682^{a)} \\
-0.3539^{b)} \\
-9.6305^{c)} \\
9.28^{d)}\end{array}$ & $\begin{array}{c}20.905 \\
-0.3644 \\
-9.9168 \\
9.55\end{array}$ & & & $\begin{array}{c}50.438 \\
-0.2901 \\
-7.8951 \\
7.60\end{array}$ & $\begin{array}{c}41.658 \\
-0.2917 \\
-7.9370 \\
7.64\end{array}$ \\
\hline $\begin{array}{c}27.260 \\
-0.3570 \\
-9.7146 \\
9.36\end{array}$ & $\begin{array}{c}15.569 \\
-0.3600 \\
-9.7980 \\
9.43\end{array}$ & & & $\begin{array}{l}33.423 \\
-0.3256 \\
-8.8660 \\
8.54\end{array}$ & $\begin{array}{c}24.756 \\
-0.3275 \\
-8.9106 \\
8.59\end{array}$ \\
\hline $\begin{array}{c}62.699 \\
-0.3487 \\
-9.4891 \\
9.14\end{array}$ & $\begin{array}{c}50.860 \\
-0.3537 \\
-9.6238 \\
9.27\end{array}$ & & & $\begin{array}{c}69.196 \\
-0.3233 \\
-8.7969 \\
8.47\end{array}$ & $\begin{array}{c}59.818 \\
-0.3286 \\
-8.9405 \\
8.62\end{array}$ \\
\hline $\begin{array}{c}20.543 \\
-0.3533 \\
-9.6043 \\
9.25\end{array}$ & $\begin{array}{c}14.155 \\
-0.3566 \\
-9.7026 \\
9.35\end{array}$ & endo & exo-7 & $\begin{array}{c}22.043 \\
-0.3166 \\
-8.6167 \\
8.30\end{array}$ & $\begin{array}{c}16.638 \\
-0.3203 \\
-8.7153 \\
8.39\end{array}$ \\
\hline
\end{tabular}

a) Heat of formation: kcal/mol, b) LUMO: eV, c) HOMO: eV, d) LUMO-HOMO

Table 4. IP Values and the Differences between LUMO and HOMO Energy Levels

\begin{tabular}{clccc}
\hline \hline & & exo-1 & exo-5 & exo-7 \\
\hline \multirow{2}{*}{ AM1 } & IP & 8.86 & 8.80 & 8.62 \\
& L-H & 8.54 & 8.47 & 8.30 \\
PM3 & IP & 8.91 & 8.94 & 8.71 \\
& L-H & 8.59 & 8.62 & 8.39 \\
PM5 & IP & 8.83 & 8.88 & 8.57 \\
& L-H & 9.02 & 8.88 & 8.79
\end{tabular}

a) The conjugation energy between the phenyl and azadiene moieties seems to be underestimated, affecting the HOMO energy level. The HOMO energy levels of several conformational isomers based on the DFT-calculated geometries [B3LYP/6-31(D)] range from 8.63 to $8.88 \mathrm{eV}$.

DHP) as shown in Chart 2.

FMO data based on AM1 and PM3 calculations are compared in Table 3. The dimethylpyrazine (first entry) that did not exhibit the breakage activity also cannot isomerize to the exo-type isomer, because the heat of formation $\left(\Delta H_{\mathrm{f}}\right)$ of the exo-type is considerably higher than that of the endo-type due to the latter's aromaticity. If the pyrazine were converted into the exo-type, the breakage activity could be significantly higher than the parent DHPs. It is predicted that isomerization to an enamine structure is required and the endo- to exotype ratio affects the breakage activity. The breakage activity is as strong as the $\Delta \Delta H_{\mathrm{f}}$ is small, according to the differences $\left(\Delta \Delta H_{\mathrm{f}}=\Delta H_{\mathrm{f}}\right.$ of exo-type $-\Delta H_{\mathrm{f}}$ of endo-type $)$ obtained from Table 3 . When the endo-type is converted into the exo-type, the LUMO-HOMO $(\mathrm{L}-\mathrm{H})$ energy gap becomes smaller, resulting in enhancement ${ }^{15)}$ of the reactivity of DHPs.

The assay of the breakage activity was performed in incubation periods of 1 or $3 \mathrm{~h}$ in aqueous solution. The exo-type isomer was consumed rapidly at an early stage, and then the equilibrium (endo-type $\Leftrightarrow$ exo-type) shifted to the right towards the formation of the exo-type. Thus, we evaluated the IP values of the exo-type structures.

As summarized in Table 4, the IP and L-H gaps follow the
Table 5. The Differences $\left(\Delta \Delta H_{\mathrm{f}}\right)$ in the Heat of Formation $\left(\Delta H_{\mathrm{f}}\right)$ between exo-Type and endo-Type DHPs, Considering the Participation of Water Molecule $(\mathrm{EPS}=78.4)$

\begin{tabular}{llrrr}
\hline \hline & & endo-Type & exo-Type & \multicolumn{1}{c}{$\Delta H_{\mathrm{f}}$} \\
\hline \multirow{2}{*}{ PM5 } & $\mathbf{1}$ & 0.946 & 6.687 & 5.741 \\
& $\mathbf{5}$ & 29.872 & 35.147 & 5.275 \\
& $\mathbf{7}$ & -4.736 & -4.148 & 0.588 \\
AM1 & $\mathbf{1}$ & 14.410 & 20.029 & 5.619 \\
& $\mathbf{5}$ & 47.462 & 52.854 & 5.392 \\
& $\mathbf{7}$ & 8.231 & 8.435 & 0.204 \\
& $\mathbf{1}$ & 4.230 & 13.184 & 8.954 \\
& $\mathbf{5}$ & 37.914 & 46.602 & 8.688 \\
& $\mathbf{7}$ & 3.178 & 5.840 & 2.662 \\
\hline
\end{tabular}

trend $(\mathbf{7}>\mathbf{5}>\mathbf{1})$ of the breakage activity: as the values become smaller, the activity increases. To determine the solvent effect on the endo/exo ratios of DHPs, the heats of formation $\left(\Delta H_{\mathrm{f}}\right)$ were calculated using the COSMO continuum solvation models. The differences $\left(\Delta \Delta H_{\mathrm{f}}\right)$ in $\Delta H_{\mathrm{f}}$ between endotype (1,4-diazadiene) and exo-type (1-azadiene) isomers are summarized in Table 5. All calculation methods $(E P S=78.4)$ showed that the energy difference of 7 is considerably smaller than those of $\mathbf{1}$ and $\mathbf{5}$, indicating that isomerization to the exo-type easily occurs. The isomerization to the exo-type isomer is favorable in the order of $\mathbf{7}>\mathbf{5}>\mathbf{1}$, in agreement with the breakage activity.

In addition, the bond dissociation energies (BDE) of exotype DHPs were calculated for comparison to the order of the breakage activity, because the DNA breakage reaction proceeded by the generation of radical species from DHPs. In the ESR spectrum, ${ }^{3)}$ carbon-centered radical signals were detected as DMPO-adducts (detailed results will be described in a following paper). As a precursor of the radical species (as shown in Chart 4) which was speculated by the orbital shapes on SOMO of the exo-type DHP and obtuse angle signals in the ESR spectra, the structure $(\cdot N-\mathrm{R})$ was postulated on the basis of the bond energies of $98.8(\mathrm{H}-\mathrm{C})$ and 93.4 $(\mathrm{H}-\mathrm{N}) \mathrm{kcal} / \mathrm{mol}$. The order of BDE values for the comparison of exo-type DHP and a precursor structure $(\cdot \mathrm{N}-\mathrm{R})$ were 7: $27.07<\mathbf{5}: 29.24<\mathbf{1}: 30.51$ by PM5, 7: $29.08<\mathbf{5}: 30.83<\mathbf{1}$ : 31.73 by AM1 and 7: $25.57<5: 27.42<\mathbf{1}: 29.85$ by PM3, supporting the breakage activity. As the BDE value gets smaller, the breakage activity increases, indicating that facility towards radical generation is also important for activity. The generation of a radical species from DHPs, initiating the change from a precursor structure $(\cdot \mathrm{N}-\mathrm{R})$ to a carbon-centered radical species, needs to be studied further in order to determine the driving force of this reaction.

While there have been few reports ${ }^{16-19)}$ related to carboncentered radicals, we propose that the DNA breakage activity is due to carbon-centered radicals generated from DHPs as described in a previous paper. ${ }^{4)}$ Furthermore, there are few reports ${ }^{19-21)}$ related to DHPs with DNA strand-breakage activity except for ours, and even fewer reports concerning the mechanism of the breakage activity. The IP hypothesis that we propose is but one step towards explaining the mechanism. Although the hypothesis that the breakage activity is as strong as the IP values are small is incomplete at present, it is useful for the synthetic design of compounds having DNA strand-breakage activity. 

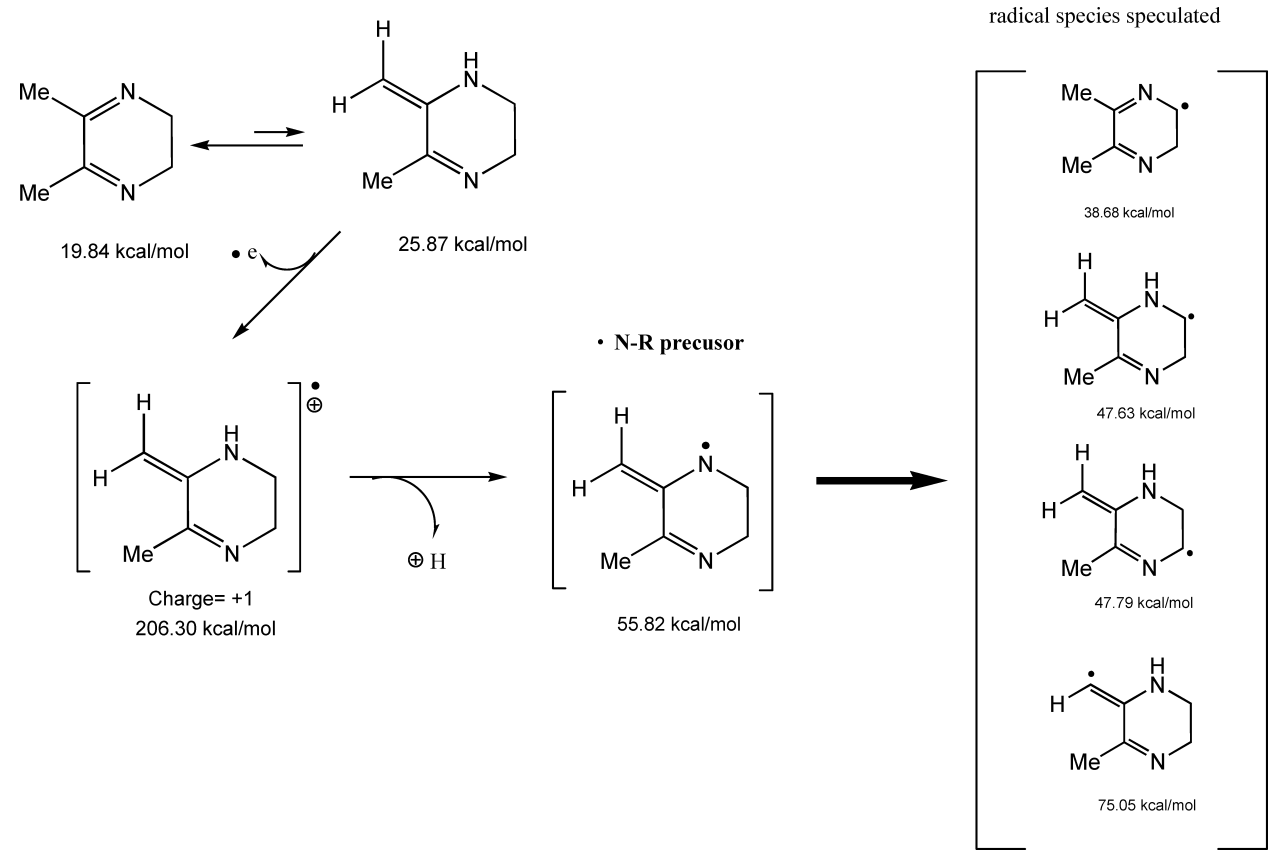

Chart 4. The Heats of Formation Energy Calculated on the Basis of PM5

Acknowledgements This work was supported in part by a Grant-in-Aid for Scientific Research (C) from the Japan Society for the Promotion of Science (JSPS).

\section{References and Notes}

1) Yamaguchi T., Kashige N., Mishiro N., Miake F., Watanabe K., Biol. Pharm. Bull., 19, 1261-1265 (1996).

2) Kashige N., Yamaguchi T., Miake F., Watanabe K., Biol. Pharm. Bull., 23, 1281-1286 (2000).

3) Yamaguchi T., Matsumoto S., Watanabe K., Tetrahedron Lett., 39, 8311-8312 (1998).

4) Kashige N., Takeuchi T., Matsumoto S., Takechi S., Miake F., Yamaguchi T., Biol. Pharm. Bull., 28, 419-423 (2005).

5) Yamaguchi T., Ito S., Iwase Y., Watanabe K., Harano K., Heterocycles, 51, 2305-2309 (1999).

6) Yamaguchi T., Ito S., Iwase Y., Watanabe K., Harano K., Heterocycles, 53, 1677-1680 (2000).

7) Yamaguchi T., Eto M., Harano K., Kashige N., Watanabe K., Ito S., Teterahedron, 55, 675-686 (1999).

8) Yamaguchi T., Nomura H., Matsunaga K., Ito S., Takata J., Karube Y., Biol. Pharm. Bull., 26, 1523-1527 (2003).

9) Takechi S., Yamaguchi T., Nomura H., Minematsu T., Nakayama T., Mutat. Res., 560, 49-55 (2004).

10) Kashige N., Yamaguchi T., Mishiro N., Hanazono H., Miake F., Watanabe K., Biol. Pharm. Bull., 18, 653-658 (1995).
11) Hepworth J. D., "Organic Syntheses," Collective Vol. 5, ed. by Baumgarten H. E., Wiley, New York, 1973, pp. 27-29.

12) Compound 5: semi-solid. FAB-MS $m / z$ : $172.1084\left[(\mathrm{M}+\mathrm{H})^{+}, \mathrm{C}_{11} \mathrm{H}_{13} \mathrm{~N}_{2}\right.$ (MW: 172.1079)] and compound 6: semi-solid. FAB-MS $\mathrm{m} / \mathrm{z}$ : $227.1548\left[(\mathrm{M}+\mathrm{H})^{+}, \mathrm{C}_{15} \mathrm{H}_{19} \mathrm{~N}_{2}\right.$ (MW: 227.3293)]. The structural identification was performed by ${ }^{1} \mathrm{H}$ - and ${ }^{13} \mathrm{C}-\mathrm{NMR}$ analyses. The details will be described in a separate paper preparing it now.

13) Maruoka H., Kashige N., Miake F., Yamaguchi T., Chem. Pharm. Bull., 53, 1359-1361 (2005).

14) Mibu N., Yukawa M., Kashige N., Iwase Y., Goto Y., Miake F., Yamaguchi T., Ito S., Sumoto K., Chem. Pharm. Bull., 51, 27-31 (2003).

15) Fleming I., "Frontier Orbitals and Organic Chemical Reactions," Wiley, London, 1976, pp. 37-40.

16) August O., Falijoni-Alario A., Leite L. C. C., Noberga F., Carcinogenesis, 5, 781-784 (1984).

17) Leite L. C. C., August O., Arch. Biochem. Biophys., 270, 560-572 (1989).

18) August O., Free Radical Biology Medicine, 15, 329-336 (1993).

19) Hiramoto K., Inoue M., Maeda K., Kato T., Kikugawa K., Jpn. J. Toxicol. Environ. Health, 40, 412-421 (1994).

20) Bunke A., Zerbe O., Schmid H., Burmeister G., Merkle H. P., Gander B., J. Pharm. Sci., 89, 1335-1341 (2000).

21) Teixeira P. C., Onuki J., Medeiros M. H. G., Dornemann D., Mascio P. D., Biol. Chem., 382, 913-918 (2001). 